\title{
Significance of prediabetes as a nosological entity
}

\author{
Ladislav Stepanek ${ }^{\mathrm{a}, \mathrm{b}}$, Dagmar Horakova ${ }^{\mathrm{a}}$, Marie Nakladalovaa ${ }^{\mathrm{b}}$, Lubica Cibickovac, David Karasekc, Josef Zadrazilc
}

\begin{abstract}
Prediabetes is a glucose metabolism disorder considered as a distinct nosological entity which strongly predicts the development of type 2 diabetes mellitus. This nosological entity itself is a serious condition indicating an increased risk of atherosclerotic and oncological complications. In patients with prediabetes, other components of metabolic syndrome are usually present, such as arterial hypertension, obesity or dyslipidaemia, further increasing an individual's risk of morbidity and mortality. Prediabetes is a long-developing disorder which offers enough time for early diagnosis and intervention; it may even be reversible. This review summarizes current knowledge on the definition, detection, epidemiology, cardiovascular and other consequences of prediabetes. It also gives suggestions for future research, along with recommendations for clinical practice.
\end{abstract}

Key words: prediabetes, impaired fasting glucose, impaired glucose tolerance, prevalence, cardiovascular complications, cancer

Received: May 14, 2018; Accepted with revision: September 13, 2018; Available online: September 24, 2018 https://doi.org/10.5507/bp.2018.057

${ }^{a}$ Department of Public Health, Faculty of Medicine and Dentistry, Palacky University Olomouc, Czech Republic ${ }^{b}$ Department of Occupational Medicine, University Hospital Olomouc and Faculty of Medicine and Dentistry, Palacky University Olomouc, Czech Republic

${ }^{c}{ }^{\text {rd }}$ Department of Internal Medicine - Nephrology, Rheumatology and Endocrinology, University Hospital Olomouc and Faculty of Medicine and Dentistry, Palacky University Olomouc, Czech Republic

Corresponding author: Ladislav Stepanek, e-mail: stepanek.ladislav@gmail.com

\section{INTRODUCTION AND DEFINITIONS}

Prediabetes is currently a distinct nosological entity characterized by impaired glucose metabolism, with levels that are above normal but fall below the criteria for diabetes mellitus (DM). The term prediabetes itself implies a condition preceding the development of type 2 DM (T2DM) which in most cases is true, as seen below. At a quantitative level, however, there is no globally consistent definition as professional societies use different criteria. This complicates the comparison and interpretation of data from various parts of the world, making them less clear. There is even no uniform consensus about the term prediabetes which is used mainly by the American Diabetes Association (ADA) (ref. $\left.{ }^{1}\right)$. The World Health Organization (WHO), preferring the term intermediate hyperglycemia, defined prediabetes as the presence of at least one of the following conditions: (1) impaired fasting glucose (IFG), that is, a condition characterized by fasting plasma glucose (FPG) ranging from 6.1 to $6.9 \mathrm{mmol} / \mathrm{L}$ and, at the same time (if measured), 120-minute plasma glucose below $7.8 \mathrm{mmol} / \mathrm{L}$ after a $75 \mathrm{~g}$ oral glucose toler- ance test (OGTT); (2) impaired glucose tolerance (IGT), that is, a condition characterized by FPG below $7 \mathrm{mmol} / \mathrm{L}$ and, at the same time, 120-minute plasma glucose between 7.8 and $11.0 \mathrm{mmol} / \mathrm{L}$ after a standard OGTT (ref. ${ }^{2}$ ). The ADA definition of prediabetes has a different lower cutoff for IFG, ranging from 5.6 to $6.9 \mathrm{mmol} / \mathrm{L}$ and (since 2010) an additional criterion of glycated hemoglobin A1c (HbAlc) between 39 and $47 \mathrm{mmol} / \mathrm{mol}\left(\right.$ ref. $^{3}$ ). Apart from IFG, there are also variations in HbAlc cut-offs, as evidenced, for example, by the $42-47 \mathrm{mmol} / \mathrm{mol}$ range used in Canada ${ }^{4}$. Table 1 summarizes the criteria for prediabetes used by various professional societies.

As demonstrated below, it is apparent that professional societies using the criteria with a wider IFG (and $\mathrm{HbA1c}$ ) range report higher prevalence and lower complication rates of prediabetes. Reversely, a narrower IFG range (with a lower cut-off as the WHO criteria) means lower prevalence and higher complication rates of prediabetes.

So far, $\mathrm{HbA} 1 \mathrm{c}$ has not been globally introduced as a criterion of prediabetes. This relatively novel criterion has been assessed by numerous studies, most of which consid-

Table 1. Prediabetes criteria of various professional societies.

\begin{tabular}{lccc}
\hline & WHO (ref. $^{2}$ ) & ADA (ref. $\left.{ }^{3}\right)$ & CDA (ref. $\left.{ }^{4}\right)$ \\
\hline At least 1 of the conditions (lines): & & & \\
Fasting plasma glucose (mmol/L) & $6.1-6.9$ & $5.6-6.9$ & $6.1-6.9$ \\
2-hour oral glucose tolerance test (mmol/L) & $7.8-11.0$ & $7.8-11.0$ & $7.8-11.0$ \\
Hemoglobin A1c (mmol/mol) & & $39-47$ & $42-47$ \\
\hline
\end{tabular}


er this step beneficial, pointing to increased sensitivity of diagnosing prediabetes if $\mathrm{HbAlc}$ is used in combination with the above original methods ${ }^{5-9}$. By contrast, Chilelli et al. reported that in a cohort of 501 individuals, HbAlc (the ADA interval) was not a sufficiently specific marker for the diagnosis of prediabetes ${ }^{10}$. Nevertheless, health organizations worldwide agree on a need for standardization of HbA1c diagnostic assays. Therefore, the International Federation of Clinical Chemistry (IFCC) developed a reference measurement procedure based on a concept of metrological traceability to achieve global standardization. According to the IFCC, patients' HbAlc concentrations should be reported using the International System of Units (i.e. in $\mathrm{mmol} / \mathrm{mol}$ ). However, the US National Glycohemoglobin Standardization Program (NGSP) supports reporting $\mathrm{HbA} 1 \mathrm{c}$ concentrations differentely (in \%) based on the Diabetes Control and Complications Trial. These two units can be converted using the following formula ${ }^{11}$ :

$$
\operatorname{NGSP}(\%)=0.0915 \times \operatorname{IFCC}(\mathrm{mmol} / \mathrm{mol})+2.15
$$

The three diagnostic methods are not 100 percent concordant with one another. Some studies have shown that FPG alone may be inadequate for detecting prediabetes while higher detection rates were reported when OGTT and $\mathrm{HbA} 1 \mathrm{c}$ were used ${ }^{12}$. But even these two criteria may be discordant, as suggested by Camacho et al. in their study $(n=218)$ demonstrating a significant difference between these two tests for the diagnosis of prediabetes among Hispanic and non-Hispanic white populations ${ }^{13}$.

The advantages of HbA1c analysis over FPG analysis are independence from the feeding/fasting cycle, lower biological variability of the obtained results and an easier preanalytical phase due to the higher stability of $\mathrm{HbAlc}$. On the other hand, the disadvantages are dependence on the mean erythrocyte life span and also HbA1c interference with pathological forms of hemoglobin during the analysis process ${ }^{14}$. The preanalytical phase is a key part of the FPG determination as various anticoagulants, stabilizing additives and other conditions influence the obtained results. In this way, consistent adherence to standardized measurement procedures is crucial for applying established cut-offs for IFG.

\section{PREVALENCE OF PREDIABETES}

While there are estimates of the worldwide prevalence of DM (age-standardized prevalence of $8.5 \%$ in 2014) (ref. ${ }^{15}$ ), no such relevant estimates are available for prediabetes. Part of this is surely due to missing data from many regions of the world, together with the globally varied criteria for diagnosing this nosological entity. Glucose metabolism abnormalities have rapidly risen in prevalence in both developed and developing countries of the world ${ }^{16}$. Prediabetes is estimated to affect more than 470 million people throughout the world in 2030 ( ref. $^{17}$ ). Still at the global level, as many as $7.3 \%$ of adults aged 20-79 years suffer from IGT. More than $70 \%$ of them live in middle- and low-income countries; one half of them are younger than 50 years of age. By 2045, the number of people aged 20-79 years with IGT is projected to increase to $8.3 \%$ (ref. $^{18}$ ). About $7 \%$ of the adult population worldwide live with either IGT or IFG. The two abnormalities are estimated to overlap in $25 \%$ of Caucasians ${ }^{17}$. The global prevalence of IFG is estimated at 5\%; however, this is rather tentative given the two criteria for diagnosing IFG (ref. ${ }^{12}$ ). Globally, the mean FPG levels have been observed to rise. In 2008, global age-standardized mean FPG was $5.50 \mathrm{mmol} / \mathrm{L}$ (95\% confidence interval [CI] 5.37-5.63) for men and $5.42 \mathrm{mmol} / \mathrm{L}$ (5.29-5.54) for women, having risen by $0.07 \mathrm{mmol} / \mathrm{L}$ and $0.09 \mathrm{mmol} / \mathrm{L}$ per decade, respectively ${ }^{16}$. The globally uniform criteria for diagnosing IGT enables an easy comparison of its prevalence in various parts of the world as indicated in Fig. 1.

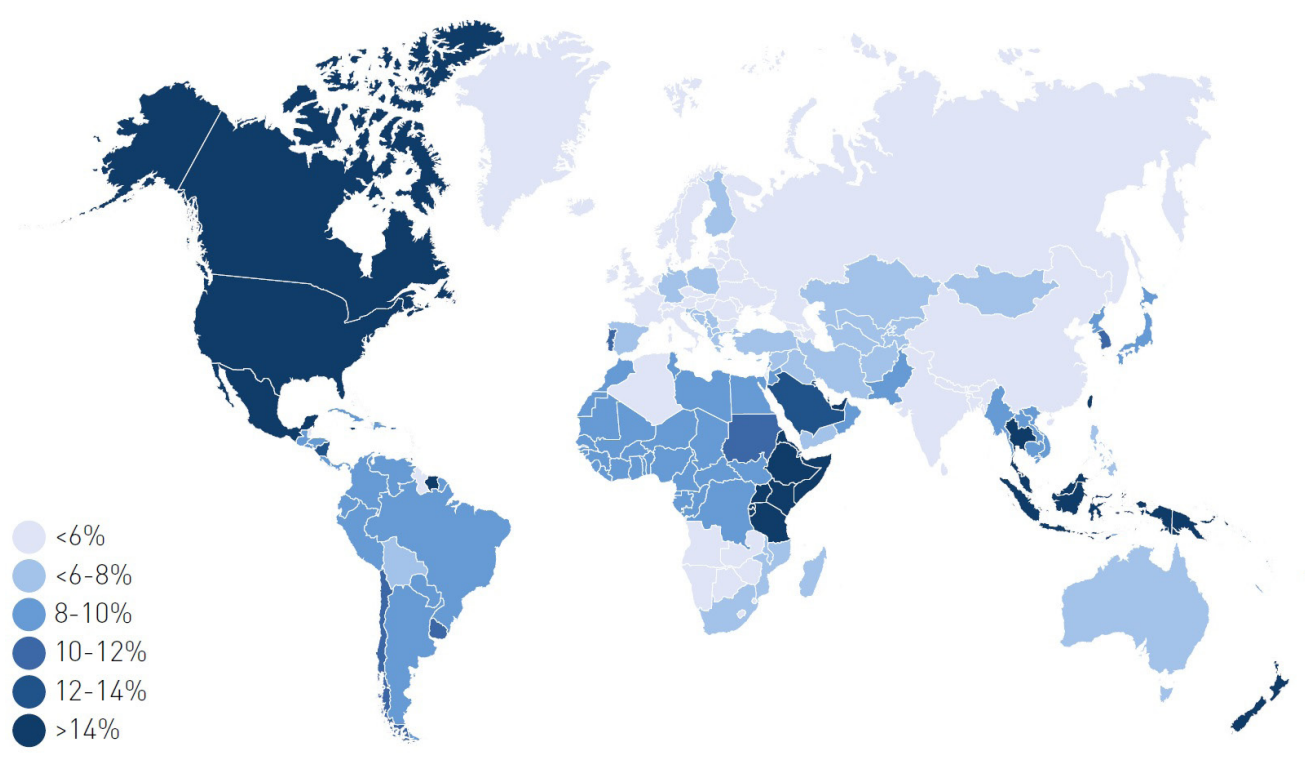

Fig. 1. Age-adjusted prevalence (\%) of impaired glucose tolerance (20-79 years), 2017 (ref. $\left.{ }^{18}\right)$. 
Data on the prevalence of prediabetes show considerable regional differences. Very accurate data with time trends are obtained from the long-term US populationwide National Health and Nutrition Examination Survey (NHANES). This shows that based on IFG and HbAlc measurements (both the ADA criteria), $33.9 \%$ of US adults over 18 years of age had prediabetes in 2015 (48.3\% of individuals over 65 years). This corresponds to 84.1 million of prediabetics in the USA in 2015 (ref. ${ }^{19}$ ). Such high prevalence may also be affected by the fact that the ADA criteria has the widest IFG and $\mathrm{HbAlc}$ range. The increase in prevalence between the 1999-2002 and 2007 2010 NHANES cycles was higher for females than for males. However, prediabetes is still more prevalent in US males. Remarkably, the prevalence of IFG (the ADA criteria) remained relatively stable, rising from $23.9 \%$ to $26.6 \%$ between the same cycles, in contrast with HbA1c (the ADA criteria) increasing from $9.5 \%$ to $17.8 \%$ (ref. $^{20}$ ).

Many European countries lack adequate populationrepresentative data for estimating the prevalence of prediabetes. There are certainly great regional variations across Europe in the prevalence of hyperglycemic disorders $^{21}$. Overall, however, as many as 5.5\% (36 million) of European adults aged 20-79 years are estimated to live with IGT. By 2045, the prevalence of IGT in Europe is expected to increase to $6.1 \%$. Although this is one of the lowest prevalence rate worldwide, it is disturbing given the significant phenomenon of population aging ${ }^{18}$.

\section{PROGRESSION FROM PREDIABETES TO T2DM}

Prediabetes is a risk factor for the development of T2DM. Estimates indicate that most individuals (up to $70 \%$ ) with prediabetes eventually develop T2DM (ref. ${ }^{22}$ ). Data on the annual incidence of progression from prediabetes to T2DM are rather varied, depending on both the prediabetes diagnostic criteria used and conditions or interventions in the studied individuals. When considering data on prediabetics with no targeted intervention, a large meta-analysis of prospective studies $(n=29,475)$ from 1979 to 2004 reported annual incidence rates for the progression of $6.1-9.2 \%$ in individuals with isolated IFG (the WHO criteria), 4.4-6.4\% in those with isolated IGT and $10-15 \%$ for patients with both disorders combined. When these data are summed, the annual incidence of progression from prediabetes to T2DM is $5-10 \%$ (ref. $^{23}$ ). The risk of transition from prediabetes to established T2DM is not evenly distributed in the prediabetes diagnosis intervals and increases towards the upper limits of IGT and IFG $\left(\right.$ ref. $\left.^{24,25}\right)$. The predictors of progression from prediabetes to T2DM include weight gain, the development/progression of insulin resistance (IR), decreased insulin secretion or an adverse adipocytokine profile ${ }^{26}$.

Numerous studies have shown a drop in the incidence of progression from prediabetes to T2DM following both lifestyle and pharmacological measures. Among the pharmacological measures, metformin, acarbose, rosiglitazone and pioglitazone seem to be the most powerful drugs, as evidenced by several randomized controlled trials ${ }^{27}$. Some studies have also suggested a possible reverse process of transition from confirmed prediabetes to normal glucose levels due to the aforementioned measures ${ }^{17}$.

\section{PREDIABETES AND INCREASED RISK OF OTHER DISEASES}

\section{Increased risk of cardiovascular disease (CVD)}

In 2017, approximately 4 million people aged between 20 and 79 years were estimated to die of diabetes-related causes, with the greatest proportion of them dying of CVD (ref. ${ }^{18}$ ). The overall risk of CVD in diabetics is 2-4 times higher than in those without DM ( ref. $^{28}$ ). However, the increased risk of CVD is already present at the prediabetes stage, as evidenced by numerous studies. The presence of prediabetes is estimated to increase the risk of CVD by approximately $20 \%$ as compared with healthy individuals ${ }^{29}$, as confirmed by a large meta-analysis of prospective studies including more than a total of $1,600,000$ participants which showed the relative risk (RR) of overall CVD morbidity to be 1.13 for isolated IFG (the ADA criteria), 1.26 for IFG (the WHO criteria) and 1.3 for IGT, and of all-cause mortality to be $1.13,1.13$ and 1.32, respectively ${ }^{30}$. As in the risk of progression from prediabetes to T2DM, the risk of CVD increases towards the upper limits of IGT and IFG diagnostic cut-offs ${ }^{31}$. Some authors have even reported evidence of increased CVD risk as early as at the stage of normal glucose levels just below the prediabetes threshold ${ }^{32}$. A prospective study $(n=10,913)$ showed increased risk of CVD morbidity of 1.53 (95 \% CI 1.22-1.91) in individuals with FPG 5.3-5.5 $\mathrm{mmol} / \mathrm{L}$ as compared with those with FPG $4.4 \mathrm{mmol} / \mathrm{L}$ (ref. $\left.{ }^{33}\right)$.

Many studies consider IGT a stronger predictive factor for CVD morbidity and mortality than IFG. A large study composed of 10 European cohort studies confirmed the presence of IGT as an independent predictive factor for overall and CVD mortality. However, this was not true for IFG (the WHO criteria) alone ${ }^{34}$. Similar findings were reported by the Hoorn Study in the Netherlands ${ }^{35}$ and for CVD morbidity by the Framingham Offspring Study ${ }^{36}$, a Finnish study by Lind et al. ${ }^{37}$ or the Funagata study in Japan $^{38}$. By contrast, a meta-analysis by Ford et al. failed to show a difference in the predictive power of IFG (the WHO criteria) and IGT for the risk of CVD (ref. ${ }^{39}$ ). In addition to IFG and IGT, there is relative agreement on the predictive power of increased $\mathrm{HbAlc}$ which seems to be at least the same as that of the two disorders, for relationships between this marker and both CVD morbidity $^{40,41}$ and all-cause mortality ${ }^{42}$.

\section{Macrovascular complications}

A pathogenetically important role in the development of macrovascular complications in diabetics is played by acceleration of atherosclerotic changes in arteries ${ }^{43}$. Today, however, reliable evidence is available on acceleration of this degenerative process at both molecular ${ }^{44}$ 
and clinical levels ${ }^{45}$ already at the prediabetes stage. In real practice, these degenerative processes are greatly contributed to by the concurrent presence of multiple risk factors, such as arterial hypertension, dyslipidemia, with mutually potentiating effects, very often accumulated in metabolic syndrome (MetS) $\left(\right.$ ref. $\left.^{46}\right)$. The relative importance of glucose metabolism disorders is likely to decrease with age, probably as a result of development of other cardiometabolic risk factors ${ }^{29}$.

\section{Coronary artery disease (CAD)}

There are numerous studies showing a higher prevalence of prediabetes in patients with CAD and, moreover, some prospective studies show a higher risk of CAD in prediabetics. A meta-analysis of prospective cohort studies $(n=527,021)$ revealed increased risks of CAD in participants with IFG defined both as the ADA or WHO criteria (RR 1.11, 95\% CI 1.02-1.21; and RR 1.18, 95\% CI $1.10-1.28$, respectively) (ref. $\left.{ }^{47}\right)$. Thus, not only prediabetes is likely to play a role in the development of CAD, but numerous studies have shown a poorer prognosis (higher reoccurrence and overall mortality rates) when compared with individuals without glucose metabolism disorders ${ }^{48}$.

\section{Stroke}

The mean prevalence of prediabetes in patients with stroke or transient ischemic attack in the acute phase is $37 \%$. The lowest and highest rates were 29\% in China and $53 \%$ in the USA, respectively; once again, this is clearly higher than the prevalence of prediabetes in the general population $^{12}$. A large meta-analysis of cohort studies $(n=760,925)$ found, after adjustment for common risk factors, an independent association between IGT, or combination of IFG (the ADA criteria) and IGT, and an increased risk of future stroke (RR 1.2, 95\% CI 1.07-1.35) $\left(\right.$ ref. $\left.{ }^{49}\right)$. Prediabetes, in particular the presence of IGT, is considered an independent risk factor for the development of stroke and a strong predictor of its recurrence by most studies ${ }^{12}$. In addition to the increased risk of stroke, prediabetes is known to be linked to a poorer prognosis (worse neurological deficit) of patients following the event, as is the case of CAD $\left(\right.$ ref. $\left.^{50}\right)$.

\section{Peripheral arterial disease (PAD)}

Prediabetes is associated with a higher prevalence of PAD in comparison with individuals with no glucose metabolism disorder. An analysis of cross-sectional data of 3,607 US adults from the 1999-2004 NHANES revealed the lowest prevalence of PAD among persons with normal FPG (3.9\%), higher among those with IFG (5.4\%, the ADA criteria), and significantly higher among those with undiagnosed (9.2\%) and diagnosed DM (7.5\%) (ref. $\left.{ }^{51}\right)$.

\section{Microvascular complications}

In addition to the undoubted contribution of prediabetes to macrovascular complications, there have been discussions on its role in the development of long-term microvascular changes well-known in individuals with established DM, that is, retinopathy, nephropathy and neuropathy ${ }^{26}$.

\section{Retinopathy}

While many studies have shown an association between prediabetes and retinopathy, their conclusions are rather varied, depending on the methods used ${ }^{52}$. Based on findings from the Diabetes Prevention Program, approximately $8 \%$ of prediabetics have clinical signs of retinopathy ${ }^{53}$. As for the components of prediabetes, reliable evidence is only available for the association between retinopathy and IGT, as shown, after adjustment for common risk factors, by the Funagata study (odds ratio [OR] 1.63, 95\% CI 1.07-2.49); the relationship between IFG (the WHO criteria) and retinopathy was not statistically significant ${ }^{54}$. Even a large analysis of three cross-sectional studies by Wong et al. $(n=11,423)$ failed to give evidence on a clear and consistent glycemic threshold under the DM cut-off for the presence of retinopathy across different populations ${ }^{55}$. In their study of individuals without hypoglycemic medication, Cheng et al. reported $\mathrm{HbAlc}$ to discriminate prevalence of retinopathy better than FPG, with a marked increase in the prevalence of retinopathy for $\mathrm{HbAlc}$ values of $37 \mathrm{mmol} / \mathrm{mol}$ or $\mathrm{more}^{56}$.

\section{Nephropathy}

The evidence is more convincing for the impact of prediabetes on the development of nephropathy. Studies have shown that up to one third of individuals suffer from chronic kidney disease (CKD) as early as at the time of DM diagnosis. A study of 6,453 adult Americans without DM revealed that the prevalence of CKD (glomerular filtration rate [GFR] below $60 \mathrm{~mL} / \mathrm{min} / 1.73 \mathrm{~m}^{2}$ body surface area) increased from $1.2 \%$ of individuals with FPG between 4.9 and $5.3 \mathrm{mmol} / \mathrm{L}$ to $4 \%$ in those with FPG above $5.7 \mathrm{mmol} / \mathrm{L}\left(\right.$ ref. ${ }^{57}$ ). A meta-analysis of 8 cohort studies $(n=185,452)$ suggests that the RR of developing CKD as defined above is 1.12 (95\% CI 1.02-1.21) in persons with IFG (the ADA criteria) (ref. ${ }^{58}$ ). Similarly, the NHANES (1999-2006) confirmed the higher prevalence of CKD in prediabetics (17.7\%) as compared with those without glucose abnormalities (10.6\%) (ref. ${ }^{59}$ ). Glucose metabolism disorders have been shown to influence GFR. This was evidenced, for example, by the Framingham heart study in which individuals with prediabetes initially without CKD showed a GFR decreased by $9 \mathrm{~mL} / \mathrm{min} / 1.73$ $\mathrm{m}^{2}$ body surface area after 7 years ${ }^{60}$. But once again, the effect of clustered risk factors contributing to CKD must be mentioned.

Many studies have suggested that the non-diabetic range of hyperglycemia is associated with an increased risk of albuminuria, which is considered the earliest marker of diabetic nephropathy. However, it is not clear what range of glucose levels, below that of DM, increases the prevalence of albuminuria. A Korean cross-sectional study $(n=5,202)$ divided participants based on their FPG into 5 groups: < 5.0, 5.0-5.5, 5.6-6.0, 6.1-6.9, and $\geq 7.0 \mathrm{mmol} / \mathrm{L}$. In these groups, the rates of albuminuria were $4.1 \%, 6.0 \%$, $7.6 \%, 12.3 \%$, and $23.4 \%$, respectively, showing an increase in the prevalence of albuminuria not only between normal FPG and IFG, but also within the IFG range ${ }^{61}$. 


\section{Neuropathy}

While peripheral neuropathy (PN) has traditionally been considered a late complication of DM, there has been increasing evidence on its association with prediabetes. Approximately 25-62\% of individuals with idiopathic PN are reported to have prediabetes while $11-25 \%$ of prediabetics are thought to have PN and 13-21\% have neuropathic pain ${ }^{62}$. As in some of the above consequences, there is evidence that the prevalence of PN has an increasing gradient, from normoglycemic persons to those with IFG and IGT to diabetics ${ }^{63}$. The MONICA/KORA study including 195 diabetics and 198 controls classified according to their OGTT results revealed PN in $28 \%$ of diabetics, $13 \%$ of persons with IGT, $11.3 \%$ of individuals with IFG (the ADA criteria) and $7.4 \%$ of normoglycemic individuals. In the same cohort, neuropathic pain was found in $13.3 \%$ of diabetics, $8.7 \%$ of those with IGT, $4.2 \%$ of persons with IFG and $1.2 \%$ of individuals without glucose metabolism disorders ${ }^{64}$. From a qualitative perspective, $\mathrm{PN}$ is milder in prediabetics, mainly associated with impaired sensitivity and only slightly impaired motor function $^{62}$. Loss of plantar protective sensation and elevated mechanical stress are considered relevant factors in skin breakdown resulting in diabetic foot ulcerations. Prediabetic individuals seem to exhibit an altered plantar pressure distribution pattern similar to that often found in T2DM subjects ${ }^{65}$.

\section{Increased risk of cancer}

Prediabetes is also associated with increased risk of cancer. Prediabetics are approximately $15 \%$ more likely to develop cancer (diabetics, 20-25\%) than individuals with normal glucose levels and their mortality from cancer is higher by approximately $13 \%$ (ref. ${ }^{66,67}$ ). Prediabetes and cancer have many common aspects and are linked both epidemiologically and biologically. They are characterized by delayed obvious clinical manifestations as well as similar risk factors such as age, nutrition, cigarette smoking and obesity. Possible pathogenic mechanisms linking prediabetes and T2DM with cancer include hyperglycemia (associated with increased oxidative stress), hyperinsulinemia (with its long-known mitosis-stimulating effect) and alterations in the insulin-like growth factor 1 (IGF-1) system, chronic subclinical inflammation, abnormalities in sex hormone metabolism (especially estrogens) and adipokines $^{68}$.

Epidemiologically, the effect of prediabetes on increased cancer risk has been shown for breast, pancreatic, colorectal, hepatic, endometrial and gastric tissues ${ }^{68}$. The risk of developing breast cancer is approximately doubled by the presence of prediabetes, as seen from case-control studies by Crispo et al. (OR 1.94, 95\% CI 1.32-2.87) or Salinas-Martínez et al. (OR 2.08, 95\% CI 1.10-3.96) (ref. $\left.{ }^{69,70}\right)$. A meta-analysis of five studies $(n=576)$ showed a linear increase in the risk of pancreatic cancer by $13 \%$ (RR 1.13, 95\% CI 1.08-1.19) for an increase in FPG by $1 \mathrm{mmol} / \mathrm{L}$ (ref. ${ }^{71}$ ). A large meta-analysis of prospective studies $(n=4,462,151)$ also showed a significant linear association between fasting glucose levels and the risk of colorectal cancer. An increase in FPG by $1.11 \mathrm{mmol} / \mathrm{L}$ was associated with an increase in the risk of colorectal cancer by $1.5 \%$ (RR 1.015, 95\% CI 1.012-1.019) ( ref. $^{72}$ ). A meta-analysis $(n=1,384,594)$ by $\mathrm{Xu}$ et al. quantified an association between prediabetes and hepatocellular carcinoma (hazard ratio $1.21,95 \%$ CI 1.13-1.30) (ref. ${ }^{73}$ ). As compared with the above consequences of prediabetes, relatively little data are available on the relationship between prediabetes and cancer. Thus, further research is required that would provide valuable information, in particular for individuals having prediabetes for a long time without progression to T2DM.

\section{PREDIABETES DETECTION}

It is of paramount importance to perform regular preventive check-ups as these may aid in early detection of glucose metabolism disorders. Additionally, their results must not be underestimated. Waist circumference is an easily accessible parameter identifying individuals at a higher risk of glucose metabolism disorders as well as other components of MetS (ref. ${ }^{74}$ ). Therefore, this parameter should be more emphasized in the screening. It would be desirable to add $\mathrm{HbA} 1 \mathrm{c}$ analysis to routine screening for prediabetes globally as it would increase the sensitivity of prediabetes detection.

Along with the well-established measures of prediabetes, such as FPG and OGTT, new potential biomarkers need to be implemented into routine practice to become useful tools to aid in efforts for early prediabetes detection and treatment. Analysis of IR using noninvasive methods is highly desirable to be included in routine practice. The assessment of the level of IR using the Homeostatic Model Assessment (HOMA) has been repeatedly correlated with the insulin clamp method. A common use of the HOMA could help to detect the early onset of IR, which is generally considered to be a primary disorder leading to the development of other glucose metabolism disorders as well as other components of MetS. Also, adipokine analysis could find a clinical use in the near future. In this way, adiponectin and its high molecular weight (HMW) form appear to be potential biomarkers as hypoadiponectinemia plays an important causal role in the development of IR, T2DM and MetS. Moreover, serum levels of HMW adiponectin are independent of the feeding/fasting cycle ${ }^{74}$. Analytical studies have confirmed the ability of the HOMA and adiponectin levels to predict the onset of glucose metabolism disorders ${ }^{75}$. What is more, technical and economic difficulties of these biomarkers' analysis slowly lower, which could enable their incorporation into the routine practice. Fig. 2. depicts the development of glucose metabolism disorders in time with a special emphasis on their biomarkers.

\section{SUMMARY}

Prediabetes is a major challenge for both clinical and theoretical medicine. This condition not only leads to the development of T2DM in most cases but also contributes 


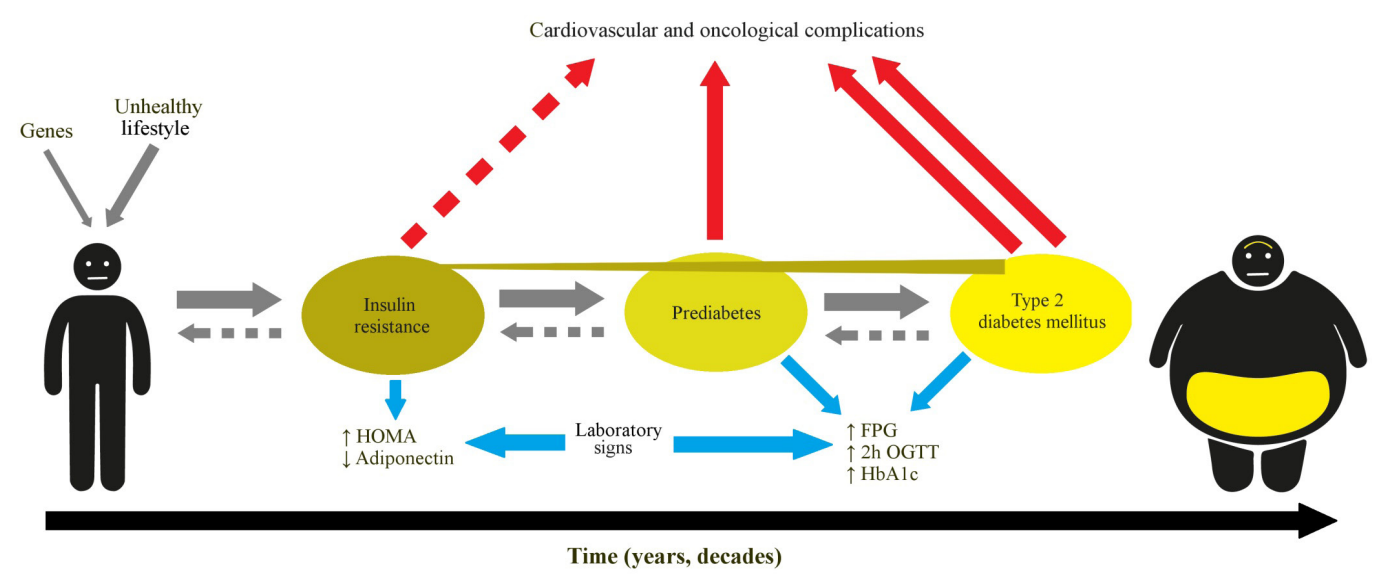

Fig. 2. Basic summary of developement of glucose metabolism disorders with their biomarkers.

HOMA - homeostatic model assessment, FPG - fasting plasma glucose, OGTT - oral glucose tolerance test, HbAlc - hemoglobin Alc

to the onset of other complications. On the other side, it is a long-developing disorder which offers enough time for early diagnosis and intervention. There is still a lack of data on the prevalence of prediabetes in various parts of the world including the Czech Republic. It must be reminded that recent years have witnessed an increase in the prevalence of child obesity with manifestation of the first signs of metabolic disorders formerly seen mainly in adults (e.g. IR and arterial hypertension). Such children have been shown to be more likely to become obese in their adulthood, facing all the negative consequences including the impact of obesity on glucose metabolism ${ }^{76}$.

The implementation of healthy lifestyle practices (regular exercise, balanced diet and avoiding cigarette smoking) has the greatest effect on preventing chronic non-infectious diseases including prediabetes. Adhering to the principles of a healthy lifestyle is a lifelong process that should address all individuals throughout the population, with systematic health education starting in childhood. Preventive measures can be classified into population-level (public health) and individual-level interventions. For individual interventions, it is critical to select an individual (or a group of individuals) to administer the particular personalized intervention according to an appropriate prediction of future CVD risk ${ }^{77}$. From a perspective of primary care providers, prediabetes detection should be targeted to patients who are most likely to benefit from diagnosis and treatment. Improving access to lifestyle intervention programs and educating providers about evidence-based treatments for prediabetes and how to effectively discuss treatment options with patients may improve both providers' and patients' engagement in T2DM prevention ${ }^{78}$.

From a clinical point of view, it is desirable to focus on the following factors: blood pressure, FPG, plasma lipids, platelet stabilization, cigarette smoking, physical activity, body weight and eating habits ${ }^{79}$. In prediabetics, an emphasis on a complex control of these factors and their optimization contributes to a decrease of CVD risk and can also contribute to a regression of prediabetes.
In many countries, apart from non-pharmacological methods, metformin administration is recommended in prediabetics with at least another one present risk factor. A network of general practitioners cooperating closely with diabetologists and other specialists is the basis for detection and treatment of prediabetes ${ }^{80}$. With the aforementioned growing prevalence, the care for prediabetics may become a domain of primary care workers more than diabetologists.

\section{CONCLUSIONS AND FUTURE PROSPECTS}

Many countries lack adequate population-representative data for estimating the prevalence of prediabetes. The presence of prediabetes means a higher risk of morbidity and mortality due to cardiovascular and oncological complications. There is reliable evidence of an increased risk of developing macrovascular as well as microvascular complications and some tumors in prediabetics. The extent of the risk as well as the numbers of studies supporting this vary depending on the particular complications. Thus, relatively few data are available on the relationship between prediabetes and cancer.

The unfavorable trends in the prevalence of prediabetes and T2DM worldwide require, in addition to a greater emphasis on their primary prevention, a greater focus not only on early detection of these two diagnoses but, ideally, to increase the effectiveness of possible interventions, on detection of metabolic disorders that precede both prediabetes and T2DM. Secondary prevention of these early disorders may be improved by adding the HOMA determination used for identifying individuals with IR to routine preventive examinations. Waist circumference and its predictive power also must not be underestimated.

\section{Search strategy and selection criteria}

Our research strategy was aimed at evaluating studies on the nosological entity of prediabetes, its definition, epidemiology and its role as a risk factor for other 
health consequences. Scientific articles from 1974 to 2018 were searched using the PubMed and Web of Science databases and references from relevant articles using the terms "prediabetes", "impaired fasting glucose", "impaired glucose tolerance", "definition", "detection“, "epidemiology“, "prevalence“, "cardiovascular disease“, "atherosclerosis", "coronary artery disease”, "stroke“, "peripheral arterial disease", "retinopathy“, "chronic kidney disease”, "nephropathy", "neuropathy" and "cancer". All searches were up to date as of April 2018. Publications from the last 10 years were preferred.

Acknowledgement: This work was supported by AZV NV18-01-00139, MZ CR - RVO (FNOL 00098892), IGA LF 2017016.

Author contributions: LS: manuscript writing, literature search; DH: literature search, critical review of the manuscript; MN: critical review of the manuscript; LC: literature search, critical review of the manuscript; DK: literature search, critical review of the manuscript; JZ: critical review of the manuscript.

Conflict of interest statement: The authors state that there are no conflicts of interest regarding the publication of this article.

\section{REFERENCES}

1. Kerrison G, Gillis RB, Jiwani SI, Alzahrani Q, Kok S, Harding SE, Shaw I, Adams GG. The Effectiveness of Lifestyle Adaptation for the Prevention of Prediabetes in Adults: A Systematic Review. J Diabetes Res 2017;2017:8493145.

2. World Health Organization, International Diabetes Federation. Definition and diagnosis of diabetes mellitus and intermediate hyperglycemia: report of a WHO/IDF consultation. 2006 [cited 2017 July 24]; [50 p.]. Available from: http://www.who.int/diabetes/publications/Definition\%20and\%20diagnosis\%20of\%20diabetes_new. pdf.

3. American Diabetes Association. Standards of Medical Care in Diabetes-2017 Abridged for Primary Care Providers. Clin Diabetes 2017;35(1):5-26

4. Punthakee Z, Goldenberg R, Katz P, Diabetes Canada Clinical Practice Guidelines Expert Committee. Definition, Classification and Diagnosis of Diabetes, Prediabetes and Metabolic Syndrome. Can J Diabetes 2018;42(Suppl1):S10-5.

5. Sohler N, Matti-Orozco B, Young E, Li X, Gregg EW, Ali MK, Bullard KM, Albu JB. Opportunistic screening for diabetes and prediabetes using hemoglobin $\mathrm{A} 1 \mathrm{C}$ in an urban primary care setting. Endocr Pract 2016;22(2):143-50.

6. Jeon JY, Ko SH, Kwon HS, Kim NH, Kim JH, Kim CS, Song KH, Won JC, Lim S, Choi SH, Jang MJ, Kim Y, Oh K, Kim DJ, Cha BY. Prevalence of diabetes and prediabetes according to fasting plasma glucose and HbA1c. Diabetes Metab J 2013;37(5):349-57.

7. Kim CH, Kim HK, Kim BY, Jung CH, Mok JO, Kang SK. Impact of hemoglobin A1c-based criterion on diagnosis of prediabetes: The Korea National Health and Nutrition Examination Survey 2011. J Diabetes Investig 2015;6(1):51-5.

8. White KA, Daneshvari S, Lilyquist J, Luo L, Steffen LE, Bivin A, Gurule N, Ducasa GM, Torres SM, Lindeman R, Sankarappan S, Berwick M. Prediabetes: The Variation between $\mathrm{HbA} 1 \mathrm{c}$ and Fasting Plasma Glucose. Int J Diabetol Vasc Dis Res 2015;Suppl2:001.

9. Karakaya J, Akin S, Karagaoglu E, Gurlek A. The performance of hemoglobin A1c against fasting plasma glucose and oral glucose tolerance test in detecting prediabetes and diabetes. J Res Med Sci 2014;19(11):1051-7.

10. Chilelli NC, Cosma C, Ragazzi E, Burlina S, Zaninotto M, Plebani M, Lapolla A. Screening with $\mathrm{HbA} 1 \mathrm{c}$ identifies only one in two indi- viduals with diagnosis of prediabetes at oral glucose tolerance test: findings in a real-world Caucasian population. Acta Diabetol 2014;51(5):875-82.

11. Weykamp C. HbA1c: a review of analytical and clinical aspects. Ann Lab Med 2013;33(6)393-400.

12. Fonville $S$, Zandbergen $A A$, Koudstaal PJ, den Hertog HM. Prediabetes in Patients with Stroke or Transient Ischemic Attack: Prevalence, Risk and Clinical Management. Cerebrovasc Dis 2014;37(6):393-400.

13. Camacho JE, Shah VO, Schrader R, Wong CS, Burge MR. Performance of $A 1 C$ versus OGTT for the diagnosis of prediabetes in a community-based screening. Endocr Pract 2016;22(11):1288-95.

14. Friedecký B, Kratochvíla J, Springer D, Prázný M, Zima T. Diabetes mellitus - laboratorní diagnostika a sledování stavu pacientů. 2015 [cited 2018 Apr 15]; [20 p.]. Available from: http://www.cskb.cz/res/ file/doporuceni/DM/DM_dop_201601.pdf. (in Czech)

15. World Health Organization. Global report on diabetes. 2016 [cited 2017 July 15]; [88 p.]. Available from: http://apps.who.int/iris/bitstr eam/10665/204871/1/9789241565257_eng.pdf.

16. Danaei G, Finucane MM, Lu Y, Singh GM, Cowan MJ, Paciorek CJ, Lin JK, Farzadfar F, Khang YH, Stevens GA, Rao M, Ali MK, Riley LM, Robinson CA, Ezzati M. National, regional, and global trends in fasting plasma glucose and diabetes prevalence since 1980: systematic analysis of health examination surveys and epidemiological studies with 370 country-years and 2.7 million participants. Lancet 2011;378(9785):31-40.

17. Tabák AG, Herder C, Rathmann W, Brunner EJ, Kivimäki M. Prediabetes: a high-risk state for diabetes development. Lancet 2012;379(9833):2279-90.

18. International Diabetes Federation. IDF Diabetes Atlas, Eighth Edition 2017. 2017 [cited 2018 Feb 11]; [150 p.]. Available from: http://www. diabetesatlas.org/resources/2017-atlas.html.

19. Centers for Disease Control and Prevention. National Diabetes Statistics Report, 2017. 2017 [cited 2017 Aug 31]; [20 p.]. Available from: https://www.cdc.gov/diabetes/pdfs/data/statistics/nationaldiabetes-statistics-report.pdf.

20. Bullard KM, Saydah SH, Imperatore G, Cowie CC, Gregg EW, Geiss LS, Cheng YJ, Rolka DB, Williams DE, Caspersen CJ. Secular Changes in U.S. Prediabetes Prevalence Defined by Hemoglobin A1c and Fasting Plasma Glucose: National Health and Nutrition Examination Surveys, 1999-2010. Diabetes Care 2013;36(8):2286-93.

21. Heidemann C, Du Y, Paprott R, Haftenberger M, Rathmann W, Scheidt-Nave C. Temporal changes in the prevalence of diagnosed diabetes, undiagnosed diabetes and prediabetes: findings from the German Health Interview and Examination Surveys in 1997-1999 and 2008-2011. Diabet Med 2016;33(10):1406-14.

22. Nathan DM, Davidson MB, DeFronzo RA, Heine RJ, Henry RR, Pratley $\mathrm{R}$, Zinman B. Impaired fasting glucose and impaired glucose tolerance: implications for care. Diabetes Care 2007;30(3):753-9.

23. Gerstein HC, Santaguida P, Raina P, Morrison KM, Balion C, Hunt D Yazdi H, Booker L. Annual incidence and relative risk of diabetes in people with various categories of dysglycemia: a systematic overview and meta-analysis of prospective studies. Diabetes Res Clin Pract 2007;78(3):305-12.

24. Forouhi NG, Luan J, Hennings S, Wareham NJ. Incidence of Type 2 diabetes in England and its association with baseline impaired fasting glucose: the Ely study 1990-2000. Diabet Med 2007;24(2):200-7.

25. Tirosh A, Shai I, Tekes-Manova D, Israeli E, Pereg D, Shochat T, Kochba I, Rudich A. Normal fasting plasma glucose levels and type 2 diabetes in young men. N Engl J Med 2005;353(14):1454-62.

26. Brannick B, Wynn A, Dagogo-Jack S. Prediabetes as a toxic environment for the initiation of microvascular and macrovascular complications. Exp Biol Med (Maywood) 2016;241(12):1323-31.

27. Aroda VR, Knowler WC., Crandall JP, Perreault L, Edelstein SL, Jeffries SL, Molitch ME, Pi-Sunyer X, Darwin C, Heckman-Stoddard BM, Temprosa M, Kahn SE, Nathan DM. Metformin for diabetes prevention: insights gained from the Diabetes Prevention Program/ Diabetes Prevention Program Outcomes Study. Diabetologie 2017;60(9):1601-11.

28. Fox CS, Coady S, Sorlie PD, Levy D, Meigs JB, D'Agostino RB, Wilson PW, Savage PJ. Trends in cardiovascular complications of diabetes. JAMA 2004;292(20):2495-9.

29. Færch K, Vistisen D, Johansen NB, Jørgensen ME. Cardiovascular risk stratification and management in pre-diabetes. Curr Diab Rep 2014;14(6):493 
30. Huang Y, Cai X, Mai W, Li M, Hu Y. Association between prediabetes and risk of cardiovascular disease and all cause mortality: systematic review and meta-analysis. BMJ 2016;355:i5953.

31. Coutinho M, Gerstein HC, Wang Y, Yusuf S. The relationship between glucose and incident cardiovascular events. A metaregression analysis of published data from 20 studies of 95,783 individuals followed for 12.4 years. Diabetes Care 1999;22(2):233-40.

32. Ning F, Tuomilehto J, Pyörälä K, Onat A, Söderberg S, Qiao Q, DECODE Study Group. Cardiovascular disease mortality in Europeans in relation to fasting and 2-h plasma glucose levels within a normoglycemic range. Diabetes Care 2010;33(10):2211-6.

33. Shaye K, Amir T, Shlomo S, Yechezkel S. Fasting glucose levels within the high normal range predict cardiovascular outcome. Am Heart 2012;164(1):111-6.

34. DECODE Study Group, European Diabetes Epidemiology Group Glucose tolerance and cardiovascular mortality-Comparison of fasting and 2-hour diagnostic criteria. Arch Intern Med 2001;161(3):397405.

35. De Vegt F, Dekker JM, Ruhé HG, Stehouwer CD, Nijpels G, Bouter LM, Heine RJ. Hyperglycaemia is associated with all-cause and cardiovascular mortality in the Hoorn population: the Hoorn Study. Diabetologia 1999;42(8):926-31.

36. Meigs JB, Nathan DM, D'Agostino RB, Wilson PW. Fasting and postchallenge glycemia and cardiovascular disease risk: the Framingham Offspring Study. Diabetes Care 2002;25(10):1845-50.

37. Lind M, Tuomilehto J, Uusitupa M, Nerman O, Eriksson J, IlanneParikka P, Keinänen-Kiukaanniemi S, Peltonen M, Pivodic A Lindström J. The association between $\mathrm{HbA1C}$, fasting glucose, 1-hour glucose and 2-hour glucose during an oral glucose tolerance test and cardiovascular disease in individuals with elevated risk for diabetes. PLoS One 2014;9(10):e109506.

38. Tominaga $M$, Eguchi $H$, Manaka $H$, Igarashi $K$, Kato T, Sekikawa A Impaired glucose tolerance is a risk factor for cardiovascular disease but not impaired fasting glucose. The Funagata Diabetes Study. Diabetes Care 1999;22(6):920-4.

39. Ford ES, Zhao G, Li C. Pre-diabetes and the risk for cardiovascular disease: a systematic review of the evidence. J Am Coll Cardiol 2010;55(13):1310-7.

40. Sarwar N, Aspelund T, Eiriksdottir G, Gobin R, Seshasai SR, Forouhi NG, Sigurdsson G, Danesh J, Gudnason V. Markers of dysglycaemia and risk of coronary heart disease in people without diabetes: Reykjavik prospective study and systematic review. PLoS Med 2010;7(5):e1000278.

41. Van't Riet E, Rijkelijkhuizen JM, Alssema M, Nijpels G, Stehouwer CD, Heine RJ, Dekker JM. HbA1c is an independent predictor of non-fatal cardiovascular disease in a Caucasian population without diabetes: a 10-year follow-up of the Hoorn Study. Eur J Prev Cardiol 2012;19(1):23-31.

42. Skriver MV, Borch-Johnsen K, Lauritzen T, Sandbaek A. HbA1C as predictor of all-cause mortality in individuals at high risk of diabetes with normal glucose tolerance, identified by screening: a follow-up study of the Anglo-Danish-Dutch Study of Intensive Treatment in People with Screen-Detected Diabetes in Primary Care (ADDITION), Denmark. Diabetologia 2010;53(11):2328-33.

43. Goldberg IJ, Dansky HM. Diabetic Vascular Disease-An Experimenta Objective. Arterioscler Thromb Vasc Biol 2006;26(8):1693-701.

44. Kramer D, Raji A, Plutzky J. Prediabetes mellitus and its links to atherosclerosis. Curr Diab Rep 2003;3(1):11-8.

45. Açar B, Ozeke O, Karakurt M, Ozen Y, Özbay MB, Unal S, Karanfil M, Yayla C, Cay S, Maden O, Topaloğlu S, Aras D, Golbasi Z, Aydogdu $\mathrm{S}$. Association of prediabetes with higher coronary atherosclerotic burden among patients with first diagnosed acute coronary syndrome. Angiology 2018 Apr 25. [Epub ahead of print] doi:10.1177/0003319718772420.

46. Dagogo-Jack S, Egbuonu N, Edeoga C. Principles and practice of nonpharmacological interventions to reduce cardiometabolic risk. Med Princ Pract 2010;19(3):167-75.

47. Xu T, Liu W, Cai X, Ding J, Tang H, Huang $Y$, Hu Y. Risk of coronary heart disease in different criterion of impaired fasting glucose: a meta-analysis. Medicine (Baltimore) 2015;94(40):e1740.

48. Kuhl J, Jörneskog G, Wemminger M, Bengtsson M, Lundman P, Kalani M. Long-term clinical outcome in patients with acute coronary syndrome and dysglycaemia. Cardiovasc Diabetol 2015;14:120.
49. Lee M, Saver JL, Hong KS, Song S, Chang KH, Ovbiagele B. Effect of pre-diabetes on future risk of stroke: meta-analysis. BMJ 2012;344:e3564.

50. Tanaka R, Ueno Y, Miyamoto N, Yamashiro K, Tanaka Y, Shimura H, Hattori N, Urabe T. Impact of diabetes and prediabetes on the shortterm prognosis in patients with acute ischemic stroke. J Neurol Sci 2013;332(1-2):45-50.

51. Gregg EW, Gu Q, Williams D, de Rekeneire N, Cheng YJ, Geiss L, Engelgau M. Prevalence of lower extremity diseases associated with normal glucose levels, impaired fasting glucose, and diabetes among U.S. adults aged 40 or older. Diabetes Res Clin Pract 2007;77(3):485-8.

52. Bansal N. Prediabetes diagnosis and treatment: A review. World J Diabetes 2015;6(2):296-303.

53. Diabetes Prevention Program Research Group. The prevalence of retinopathy in impaired glucose tolerance and recent-onset diabetes in the Diabetes Prevention Program. Diabet Med 2007;24(2):13744

54. Kawasaki R, Wang JJ, Wong TY, Kayama T, Yamashita H. Impaired glucose tolerance, but not impaired fasting glucose, is associated with retinopathy in Japanese population: the Funagata study. Diabetes Obes Metab 2008;10(6):514-5.

55. Wong TY, Liew G, Tapp RJ, Schmidt MI, Wang JJ, Mitchell P, Klein R, Klein BE, Zimmet $P$, Shaw J. Relation between fasting glucose and retinopathy for diagnosis of diabetes: three population-based crosssectional studies. Lancet 2008;371(9614):736-43.

56. Cheng YJ, Gregg EW, Geiss LS, Imperatore G, Williams DE, Zhang X Albright AL, Cowie CC, Klein R, Saaddine JB. Association of A1C and fasting plasma glucose levels with diabetic retinopathy prevalence in the U.S. population: Implications for diabetes diagnostic thresholds. Diabetes Care 2009;32(11):2027-32

57. Kramer H. Screening for kidney disease in adults with diabetes and prediabetes. Curr Opin Nephrol Hypertens 2005; 14(3):249-52.

58. Echouffo Tcheugui JB, Narayan KM, Weisman D, Golden SH, Jaar BG. Association between prediabetes and risk of chronic kidney disease: a systematic review and meta-analysis. Diabet Med 2016;33(12):1615-24.

59. Plantinga LC, Crews DC, Coresh J, Miller ER, Saran R, Yee J, Hedgeman E, Pavkov M, Eberhardt MS, Williams DE, Powe NR. Prevalence of chronic kidney disease in US adults with undiagnosed diabetes or prediabetes. Clin J Am Soc Nephrol 2010;5(4):673-82.

60. Fox CS, Larson MG, Leip EP, Meigs JB, Wilson PW, Levy D. Glycemic status and development of kidney disease: the Framingham Heart Study. Diabetes Care 2005;28(10):2436-40.

61. Won JC, Hong JW, Kim JM, Kim TN, Noh JH, Ko KS, Rhee BD, Kim DJ. Increased prevalence of albuminuria in individuals with higher range of impaired fasting glucose: the 2011 Korea National Health and Nutrition Examination Survey. J Diabetes Complications 2015;29(1):50-4.

62. Papanas N, Vinik Al, Ziegler D. Neuropathy in prediabetes: does the clock start ticking early? Nat Rev Endocrinol 2011;7(11):682-90.

63. Ziegler D, Papanas N, Vinik Al, Shaw JE. Epidemiology of polyneuropathy in diabetes and prediabetes. Handb Clin Neurol 2014;126:322.

64. Ziegler D, Rathmann W, Dickhaus T, Meisinger C, Mielck A. Neuropathic pain in diabetes, prediabetes and normal glucose tolerance: the MONICA/KORA Augsburg Surveys S2 and S3. Pain Med 2009;10(2):393-400.

65. Robinson CC, Balbinot LF, Silva MF, Achaval M, Zaro MA. Plantar pressure distribution patterns of individuals with prediabetes in comparison with healthy individuals and individuals with diabetes. J Diabetes Sci Technol 2013;7(5):1113-21.

66. Zhou XH, Qiao Q, Zethelius B, Pyörälä K, Söderberg S, Pajak A, Stehouwer CD, Heine RJ, Jousilahti P, Ruotolo G, Nilsson PM, Calori G, Tuomilehto J. Diabetes, prediabetes and cancer mortality. Diabetologia 2010;53(9):1867-76

67. Huang Y, Cai X, Qiu M, Chen P, Tang H, Hu Y, Huang Y. Prediabetes and the risk of cancer: a meta-analysis. Diabetologia 2014;57(11):2261-9.

68. Scappaticcio L, Maiorino MI, Bellastella G, Giugliano D, Esposito K. Insights into the relationships between diabetes, prediabetes, and cancer. Endocrine 2017;56(2):231-9.

69. Crispo A, Augustin LS, Grimaldi M, Nocerino F, Giudice A, Cavalcanti E, Di Bonito M, Botti G, De Laurentiis M, Rinaldo M, Esposito E, Riccardi 
G, Amore A, Libra M, Ciliberto G, Jenkins DJ, Montella M. Risk differences between prediabetes and diabetes according to breast cancer molecular subtypes. J Cell Physiol 2017;232(5):1144-50.

70. Salinas-Martínez AM, Flores-Cortés LI, Cardona-Chavarría JM, Hernández-Gutiérrez B, Abundis A, Vázquez-Lara J, GonzálezGuajardo EE. Prediabetes, diabetes, and risk of breast cancer: a case-control study. Arch Med Res 2014;45(5):432-8.

71. Pang Y, Kartsonaki C, Guo Y, Bragg F, Yang L, Bian Z, Chen Y, lona A, Millwood IY, Lv J, Yu C, Chen J, Li L, Holmes MV, Chen Z. Diabetes, plasma glucose and incidence of pancreatic cancer: A prospective study of 0.5 million Chinese adults and a meta-analysis of 22 cohort studies. Int J Cancer 2017;140(8):1781-8.

72. Shi J, Xiong L, Li J, Cao H, Jiang W, Liu B, Chen X, Liu C, Liu K, Wang G, Cai K. A Linear Dose-Response Relationship between Fasting Plasma Glucose and Colorectal Cancer Risk: Systematic Review and Metaanalysis. Sci Rep 2015;5:17591.

73. Xu WG, Qian YF, Wu J. The effect of prediabetes on hepatocellular carcinoma risk: a systematic review and meta-analysis. Minerva Med 2017;108(2):185-90.

74. Rosolová $\mathrm{H}$ et al. Preventivní kardiologie v kostce. 1st ed. Prague: Axonite CZ; 2013. (in Czech)
75. Savolainen O, Fagerberg B, Vendelbo LM, Sandberg AS, Ross AB, Bergström $\mathrm{G}$. Biomarkers for predicting type 2 diabetes development-Can metabolomics improve on existing biomarkers?. PLoS One 2017;12(7):e0177738.

76. Chung ST, Onuzuruike AU, Magge SN. Cardiometabolic risk in obese children. Ann N Y Acad Sci 2018;1411(1):166-83.

77. Golubnitschaja O, Costigliola V. General report \& recommendations in predictive, preventive and personalised medicine 2012: white paper of the European Association for Predictive, Preventive and Personalised Medicine. EPMA J 2012;3(1):14.

78. Kandula NR, Moran MR, Tang JW, O'Brien MJ. Preventing Diabetes in Primary Care: Providers' Perspectives About Diagnosing and Treating Prediabetes. Clin Diabetes 2018;36(1):59-66.

79. Rosolová H, Pelikánová T, Motoovská Z. ESC Guidelines on diabetes, pre-diabetes, and cardiovascular diseases developed in collaboration with EASD. Cor Vasa 2014;56:e189-204.

80. Perušičová J, Pelikánová T, Škrha J, Kvapil M, Šmahelová A. Doporučený postup péče o nemocné s prediabetem. 2012 [cited 2018 Apr 14]; [22 p.]. Available from: http://www.diab.cz/dokumenty/standard_prediabetes.pdf. (in Czech) 